\title{
Utility Values in Colorectal Cancer Patients Treated with Chemotherapy
}

Majid Atfannezhad

Shahid Sadoughi University of Medical Sciences and Health Services

Mehran Sharifi

Isfahan University of Medical Sciences

Mahmood Yousefi

Tabriz University of Medical Sciences

Farzan Madadizadeh

Shahid Sadoughi University of Medical Sciences and Health Services

Hosein Ameri ( $\sim$ bradfard@yahoo.com)

Shahid Sadoughi University of Medical Sciences and Health Services

\section{Research Article}

Keywords: Colorectal, Utility, EQ-5D-5L, cTTO

Posted Date: May 25th, 2021

DOI: https://doi.org/10.21203/rs.3.rs-510614/v1

License: (c) (i) This work is licensed under a Creative Commons Attribution 4.0 International License. Read Full License

Version of Record: A version of this preprint was published at Cancer Investigation on October 26th, 2021. See the published version at https://doi.org/10.1080/07357907.2021.1992632. 


\section{Abstract}

Purpose

The purpose of present study was to calculate utility values in colorectal cancer (CRC) patients by EQ-5D-5L and cTTO.

Methods

The EQ-5D-5L and CTTO were used to calculate utility values in the patients. A total of 105 patients with CRC were consecutively selected from chemotherapy ward of the Oncology Center of Omid in the second most population province, Isfahan, in Iran. The difference between mean utility values in each factor examined by the t-test and ANOWA. Finally, The BetaMix was used to identify predictors of the utility.

Results

The mean EQ-5D-5L index and cTTO values were $0.45 \pm 0.03$ and $0.51 \pm 0.02$, respectively. The anxiety and pain were the most common problems reported by the patients. Univariate analyses showed that the difference between the mean EQ-5D$5 \mathrm{~L}$ index values were significant for age, education status, income level, stage of cancer, and comorbidity number; also, showed that the difference between the mean CTTO values were significant for age, income level, employment status, stage of cancer, and comorbidity number. The BetaMix showed that lower mean utility values were significantly associated with female, aging, a low level of income, a greater number of comorbidities and advanced stage of cancer.

Conclusion

The factors of female, aging, a low level of income, advanced stage of cancer, and a greater number of comorbidities should be considered for improving values of utility. In addition, focusing on anxiety/depression through financial and social supports can be critical for the improvement in the quality of life in the patients.

\section{Introduction}

Colorectal cancer (CRC) is one of the most commonly diagnosed cancers in both sexes(1). According to the latest report by International Agency for Research on Cancer in Iran, the most common cancer types diagnosed in males were the stomach, prostate, colorectal and in females were breast, colorectal, and stomach. In both sexes combined, CRC is the second or third most common cancer found in the country(2). However, the improvement in CRC survival rate is one of the most important factors for the high prevalence of this cancer in the world and Iran. The major part of this improvement is due to interventions, such as surgery, chemotherapy, radiation, and hormonal therapy, which chemotherapy is the most common treatment approach (3). The interventions usually have short-and long- term side impacts on physical and emotional functioning that affect the patients' utility scores. For example, some evidence demonstrated that interventions including ileostomy or colostomy could cause deterioration of utility values (4-6). The assessment of utility values is especially important for the treatment of cancers because some of the side effects of the treatment may persist after the treatment is completed and other problems can arise several years later (7). To do so, EuroQoL five- dimension (EQ-5D), which is the most common indirect method in measuring utility, is commonly used. This instrument is usually employed in two version: The EQ-5D 3levels (EQ-5D-3L)(8) and the EQ-5D 5level(EQ-5D-5L)(9). All studies related to CRC patients used the EQ-5D-3L version (10-12), except one study that was used the EQ-5D-5L(13). The empirical evidence showed that EQ-5D-5L is better than EQ-5D-3L in terms of ceiling effects, sensitivity to changes, and reliability and construct validity (14). Nevertheless, the weights for both versions of EQ-5D were derived from a representative sample from the general public who have not actually experienced the health states to reflect patients' own preferences. To use patients' preferences directly in measuring utility, the direct methods including the rating scale, the standard gamble, and the time trade-of (TTO) can be used. The TTO is the most commonly used direct method for estimating utility values in health economic studies. Nevertheless, TTO is criticized for some limitations, such as different valuation procedures for states worse and better than dead. The composite TTO 
(CTTO) is an improved version of the TTO (15). Given that chemotherapy is the most common treatment for CRC and has the most economic impact on patients, measuring utility values in patients under chemotherapy is necessary to perform the economic evaluation of the treatment and to assess impact of the treatment on patients' quality of life. In addition, the use of patients' preferences directly in measuring utilities makes more realistic economic evaluations of chemotherapy interventions. No study has ever been assessed utility values using both EQ-5D and cTTO in CRC patients under only chemotherapy treatment. In light of this lack of data, this study aimed to measure the utility values in CRC under chemotherapy treatment and identify factors associated with them.

\section{Methods}

\section{Study Design and Data collection}

A number of 105 inpatients and outpatients with CRC was selected using a consecutive sampling method from chemotherapy ward of the Oncology Center of Omid, Isfahan Province, Iran over a 4-month period in 2020. Isfahan with a population of more than 5 million is the second most population province in Iran. The patients were referred to the center from all over the country.

The data was collected using face-to-face interview in the patients' rooms during a single visit. The ability to speak, the pathological confirmation of the diagnosis of cancer, and the completion of written informed consent were the inclusion criteria for the study. This study was approved by the SSU Ethics Committee, with the following identification:

IR.SSU.SPH.REC.1398.016.

\section{Health-related quality of life}

\section{EQ-5D-5L instrument}

The EQ-5D is a preference-based instrument that is widely used for assessing utility. The EQ- 5D 3levels (EQ-5D-3L)(8) and the EQ-5D 5level(EQ-5D-5L)(9) are the most commonly used versions in clinical and outcome studies. Two versions describe health in five dimensions with 3 levels for EQ-5D-3L and with 5 levels for EQ-5D-5L in each dimension. The EQ-5D-5L consists a classification system of five dimensions (mobility, self-care, usual activities, pain/discomfort, and anxiety/depression) and a visual analogue scale (VAS). Each EQ-5D-5L dimension has 5 levels of response options: no problems, slight problems, moderate problems, severe problems, and extreme problems. VAS is a line of $100 \mathrm{~mm}$ in length that respondents could determine their overall health status from 0 (the worst imaginable health) to 100 (the best imaginable health)(9). In order to use of the EQ-5D-5L, we employed Iranian interim EQ-5D-5L value set because there is not currently Iranian EQ-5D-5L value set available (16). Persian version of the EQ-5D-5L was confirmed by EuroQol group(17).

\section{Composite TTO}

We used, in addition to the EQ-5D5L, the accepted composite TTO (cTTO) approach to the valuation of utility. The approach includes the conventional TTO for valuing the health states better than dead (BTD) and lead-time TTO for valuing the health states worse than dead (WTD). To do so, first each patient was asked to choose between 10 years of full health followed by death (Life A) and 10 years of patient current health status $(x)$ followed by death (Life B). Then, 10 years in full health (t) varied until the patient is indifferent between choices $A$ and $B$. The value of the status is given by $x / t$. If the patient chose zero years in full health in comparison with 10 years in her/his current health status, we asked the patient to choose between 10 years of lead- time in full health $(L)$ followed by 10 years of full health ( $t$ ) (Life $A$ ) and 10 years of lead-time in full health followed by 10 years in her/his current health status (x) (Life B). Next, option "Life $A$ " varied until the patient is indifferent between choices $A$ and $B$. The value of the status is given by $(x-L) / t(x \leq t+L)$.

\section{Statistical analysis}


Since skewness and kurtosis, multimodality, truncations, ceiling effects, and top and bottom bounded are features of the distribution of EQ-5D utility scores, we used beta mixture (BetaMix) model which was recently developed to deal with the distributional characteristics of EQ-5D instrument. The data distribution was not normal (Kolmogorov-Smirnov test, $\mathrm{P}$ $>0.05$ ). However, we used the t-test and ANOVA instead of the non-parametric tests in assessing differences, because the findings of the non-parametric tests were similar to those of the parametric tests. STATA version 15.0 for Windows was used for all analyses.

\section{Results}

The socio-demographic characteristics of patients have been presented in details in Table 1. The mean age of the patients was 59 , and majority of them were in age group 45 to 59 years. The majority of the patients were male and secondary educated, and employed/self-employed. All of the patients had basic insurance, while only $50.48 \%$ had complementary insurance. Patients with income between $13,000,000$ to $29,999,999$ RLL at the time of the interview were the largest in the sample.

The clinical characteristics of patients is shown in Table 2. More than half of patients diagnosed with regional stage. The average of the duration of cancer was 2.4 years, and the majority of them have cancer duration $<6$ months. More than half of the patients reported having no comorbidity.

\section{Distribution of EQ-5D-5L dimensions}

Figure 1 shows patients-reported problems on each of the five EQ-5D-5L dimensions. The response "unable or extreme" was reported by the patients on all dimensions. This response on dimensions of mobility, self-care, usual activities, pain/discomfort, and anxiety/depression was $1.9 \%, 3.81 \%, 8.57 \%, 7.62 \%$, and $9.52 \%$, respectively.

\section{Univariate analyses}

The mean EQ-5D-5L index and cTTO values were $0.45 \pm 0.03$ and $0.51 \pm 0.02$, respectively. The univariate analyses showed that the difference between the mean EQ-5D-5L index values were significant for age, education status, income level, stage of cancer, and comorbidity number (Table 1 and 2). Also, the results showed that the difference between the mean cTTO values was significant for age, income level, employment status, stage of cancer, and comorbidity number (Table 1 and 2 ).

\section{Regression analyses}

Results of the BetaMix model revealed that gender, income level, comorbidity number, and stage of cancer were the predictive of EQ-5D-5L index values; and the variables of gender, age, income level and stage of cancer were the predictive of cTTO values (Pvalue<0.05) (Table 3). Among the variables, the highest income level had the most marginal effect on EQ-5D$5 \mathrm{~L}(0.919)$ and cTTO (1.01).

\section{Discussion}

The present study presents utility values using the EQ-5D-5L index and cTTO values in patients with CRC under chemotherapy treatment and impacts of socio-demographic and clinical factors on utility values. However, the high incidence of CRC is a significant health burden and public health concern in developing countries, such as Iran. Utility is a multidimensional concept that can convey important information including physical, emotional, social and cognitive domains for assessing the overall burden of cancer and the effectiveness of interventions. In addition, the findings of utility values can be used in calculating quality-adjusted life years which is a key determinant of cost- effectiveness analyses.

The mean values of EQ-5D-5L index were lower than those of two studies that have ever assessed the utility values using EQ-5D-5L in patients with CRC in Iran and China $(13,16)$. Our study found that patients had significantly lower EQ-5D-5L 
values than those of the study by Yousefi et al, on patients with CRC in Iran ( 0.45 vs 0.71$)$. The lower values of EQ-5D-5L obtained in this study compared to the results of the study by Yousefi et al. can be explained by differences in the sociodemographic profile of patients. Compared to the study by Yousefi et al, this study assessed utility in patients who were more female and older. Studies showed that utility scores in patients with CRC were lower in women than in men (18-20). The other reason for the lower mean utility values in this study in comparison with the study by Yousefi was higher mean age of patients (59 vs. 55). Aging often has a negative relationship with utility scores in patients with CRC in different contexts from countries $(13,21,22)$. The reason of this relationship can be due to a higher prevalence of multiple comorbidities and physical functioning limitations in older patients(23). Our results showed that $67 \%$ of older patients had >=2 comorbidities (data not shown).

The mean EQ-5D-5L index values of 0.45 was also lower when compared to those of 0.61 in the study carried out in China(24). A significant part of this difference can be explained by using the different tariffs of EQ-5D-5L in two study. The Chinese EQ-5D-5L tariff was derived from preferences of the Chines general public that is different from Iranian general public in terms of culture, demographic backgrounds, etc. This difference are also revealed when comparing the results with those of other developed countries including Japan (0.842)(10) and the UK (0.79)(11).

The findings of this study support that the mean utility scores were lower than those in the developed countries. It may be partly explained by the fact that in the countries with better economic countries, patients are more supported, especially economically and socially. Majority of the patients reported having financial problems (0.90) and limitations of social support (69\%). Previous studies evaluating utility values of patients with colorectal cancer found a direct association between income level and health utility scores $(13,25,26)$. Another reason for the differences in mean utility scores between countries may be related to social supports. Sapp et al, demonstrated that social support lead to better scores of utility in patients with colon, especially in terms of mental health domain(27). In addition, Sultan et al. found that patients with CRC who were socially supported having approximately $6-7$ points higher in domain of mental health than those who have no social support available(19). The use of the different versions of the EQ-5D can explain a significant part of difference between the mean utility values among the countries. We used the EQ-5D-5L, while the other two studies used the EQ-5D-3L for calculating utility. Empirical evidence shows that the EQ-5D-3L generated higher values than EQ-5D-5L because ceiling effects in EQ-5D-3L are more common than those in EQ-5D-5L.

The mean cTTO values of 0.51 were higher than those of 0.41 in the only study that assessed utility using cTTO in patients with CRC (15). The main part of this difference can be attributed to the different years were considered for the current health state in cTTO task. The number of years of the current health state was considered 10 years in cTTO task for all stages of cancer in the present study, while that was 4, 3, 2, and 1 years for stage 1, 2, 3, and 4, respectively, in the other study. Less number of years of current health state might lead to more patients trading time for an increase in quality of life, because patients believe that this short time will not an increase their quality of life.

The problems reported by patients on each of the EQ-5D dimensions showed that percentage of very severe problems reported (i.e., report "Level 5") on dimension of anxiety (9.52\%) was more than other dimensions. This frequency was consistent with the results of obtained from the emotional functioning scale of the EROTC QLQ-C30 in patients with CRC. Patients' performance on emotional functioning scale, which is theoretically very similar to the anxiety/depression of the EQ-5D, was worse among the scales of the EROTC QLQ-C30 in Germany(22) and Brazil(28). Hence, paying attention to the anxiety/depression is an important issue in management of the patients with cancer. In addition, this finding was consistent with that of the EQ-5D-5L in China(13). The distribution of problems also showed that majority of patients (76\%) experienced pain, similar to that obtained from EQ-5D for patients with CRC in China(13), the UK and the Netherlands(29).

Univariate analyses showed that the difference between the mean utility scores obtained from EQ-5D-5L was significant for education level, income level, stage of cancer, and comorbidity number; and those obtained by cTTO were significant for age, income level, employment status, stage of cancer, and a number of comorbidities. The older patients had lower utility scores, similar to those reported in patients with CRC in other countries $(13,21,22)$. Older patients often have more 
comorbidities and advanced stages of cancer, and having physical functions limitations, which impact on quality of life. Our results showed that low income was associated with low mean utility scores. Financial constraints usually limit individuals from seeking private services and make less opportunity for better healthcare(18). Most patients reported that the reason for choosing the public hospital was financial limitations. In this regard, the financial supports can help patients to have a free choice of service provider. The mean utility scores showed that higher level of education was associated with higher utility scores.

Higher education level increases patients' perceptions of their disease and treatment. This result was in line with findings reported in other studies $(13,18)$. The low level of education can often contribute to delay in the recognition of symptoms and search for care in health services. The difference between mean utility scores in variable of employment status was significant, and mean utility was higher in employed patients. The employed may lead to individuals earn more income, and subsequently, they had more opportunity for better healthcare. We also found that mean utility values in patients with advanced stage of cancer was lower than that of early stage of cancer. This finding with consistent with those reported in, Australia(30) China(13) and some European countries for patients with $\operatorname{CRC}(25,31)$. Mean utility scores by number of comorbidities showed that patients with a greater number of comorbidities had significantly lower utility scores. There is strong evidence of indirect relationship between number of comorbidities and QoL in CRC (32).

The regression analysis showed that gender, age, stage and number of comorbidities were significant independent predictors for utility scores in this study. Aging and having a larger number of comorbidities and advanced stage of cancer were significantly associated with lower EQ-5D scores. These relationships were observed in other studies conducted among colorectal cancer $(13,25,30-32)$.

The present study has some limitations that should be noted. The present study was carried out a cross-sectional survey of patients with CRC. The results from a cross-sectional survey do not all us to stablish a causal relationship between outcome variable (utility values) input variables (socio-demographic and clinical characteristics). A longitudinal study requires to be conducted for understanding how the effects of patients' characteristics on utility values. The participants were recruited the Oncology Center in one province, who were not be perfectly representative of patients; hence, generalization of the results needs to be cautious.

\section{Conclusion}

The findings of this study provide baseline health utility values for patients with CRC, which can be used by researchers in calculating quality-adjusted life years, an indicator essential for health economic evaluations, including cost-utility analyses. The study also revealed that patients with CRC have poor utility values in both EQ-5D-5L and cTTO. The depression/anxiety and pain were the most common problems reported by patients on the EQ-5D-5L. The low utility values of patients with CRC are associated with aging, low income, more advanced stages of CRC, the presence comorbidities more than 2. According to patients' reports, financial problems was the underlying cause of anxiety. It seems that is necessary to focus on financial and social supports for patients with CRC.

\section{Declarations}

Funding: This work was supported by the Shahid Sadoughi University of Medical Sciences (registration number: 7134).

Conflict of interest: The authors declare that they have no conflict of interest.

Availability of data and material: Data is not currently available because this study is a part of another study which its results have not been published.

Code Availability Not applicable 
Authors' contributions: H.A. and M.A. conceived and designed the project. M.A. collected the data. H.A., and F.M. analyzed and interpreted the data. H.A. and M.Y. drafted the manuscript. All authors read and approved the final manuscript

\section{References}

1. Bray F, Ferlay J, Soerjomataram I, Siegel RL, Torre LA, Jemal A. Global cancer statistics 2018: GLOBOCAN estimates of incidence and mortality worldwide for 36 cancers in 185 countries. CA: a cancer journal for clinicians. 2018;68(6):394424.

2. Zendehdel K. Cancer statistics in IR Iran in 2018. Basic \& Clinical Cancer Research. 2019.

3. Hoff PM, Saad ED, Costa F, Coutinho AK, Caponero R, Prolla G, et al. Literature review and practical aspects on the management of oxaliplatin-associated toxicity. Clinical colorectal cancer. 2012;11(2):93-100.

4. Conroy T, Marchal F, Blazeby JM. Quality of life in patients with oesophageal and gastric cancer: an overview. Oncology. 2006;70(6):391-402.

5. Bahayi K, Attaallah W, Yardımcı S, Bulut H, Özten E. Depression, anxiety, sexual dysfunction and quality of life in patients with ileostomy or colostomy. Turk J Colorectal Dis. 2018;28(2):69-75.

6. Keane C, Sharma P, Yuan L, Bissett I, O'Grady G. Impact of temporary ileostomy on long-term quality of life and bowel function: a systematic review and meta-analysis. ANZ journal of surgery. 2020;90(5):687-92.

7. Lipscomb J, Gotay CC, Snyder CF. Patient-reported outcomes in cancer: a review of recent research and policy initiatives. CA: a cancer journal for clinicians. 2007;57(5):278-300.

8. Group TE. EuroQol-a new facility for the measurement of health-related quality of life. Health policy. 1990;16(3):199208.

9. Herdman M, Gudex C, Lloyd A, Janssen M, Kind P, Parkin D, et al. Development and preliminary testing of the new fivelevel version of EQ-5D (EQ-5D-5L). Quality of life research. 2011;20(10):1727-36.

10. Hamashima C. Long-term quality of life of postoperative rectal cancer patients. Journal of gastroenterology and hepatology. 2002;17(5):571-6.

11. Wilson TR, Alexander DJ, Kind P. Measurement of health-related quality of life in the early follow-up of colon and rectal cancer. Diseases of the colon \& rectum. 2006;49(11):1692-702.

12. Färkkilä N, Sintonen H, Saarto T, Järvinen H, Hänninen J, Taari K, et al. Health-related quality of life in colorectal cancer. Colorectal Disease. 2013;15(5):e215-e22.

13. Huang W, Yang J, Liu Y, Liu C, Zhang X, Fu W, et al. Assessing health-related quality of life of patients with colorectal cancer using EQ-5D-5L: a cross-sectional study in Heilongjiang of China. BMJ open. 2018;8(12).

14. Buchholz I, Janssen MF, Kohlmann T, Feng Y-S. A systematic review of studies comparing the measurement properties of the three-level and five-level versions of the EQ-5D. Pharmacoeconomics. 2018;36(6):645-61.

15. Oppe M, Rand-Hendriksen K, Shah K, Ramos-Goñi JM, Luo N. EuroQol protocols for time trade-off valuation of health outcomes. Pharmacoeconomics. 2016;34(10):993-1004.

16. Ameri H, Safari H, Yousefi M, Goudarzi R, Sofi M. Interim value set for the EQ-5D-5L in Iran using the Crosswalk method. Medical Journal of The Islamic Republic of Iran (MJIRI). 2020;34(1):828-32.

17. EuroQol Research Foundation. EQ-5D-5L | about. [cited 2017 Aug 13]. Available from:https://euroqol.org/eq-5dinstruments/eq-5d-5l-about/.

18. Su M, Hua X, Wang J, Yao N, Zhao D, Liu W, et al. Health-related quality of life among cancer survivors in rural China. Quality of Life Research. 2019;28(3):695-702.

19. Sultan S, Fisher DA, Voils Cl, Kinney AY, Sandler RS, Provenzale D. Impact of functional support on health-related quality of life in patients with colorectal cancer. Cancer: Interdisciplinary International Journal of the American Cancer Society. 2004;101(12):2737-43. 
20. Orfila F, Ferrer M, Lamarca R, Tebe C, Domingo-Salvany A, Alonso J. Gender differences in health-related quality of life among the elderly: the role of objective functional capacity and chronic conditions. Social science \& medicine. 2006;63(9):2367-80.

21. Gonzalez-Saenz de Tejada M, Bilbao A, Bare M, Briones E, Sarasqueta C, Quintana J, et al. Association of social support, functional status, and psychological variables with changes in health-related quality of life outcomes in patients with colorectal cancer. Psycho-Oncology. 2016;25(8):891-7.

22. Ratjen I, Schafmayer C, Enderle J, di Giuseppe R, Waniek S, Koch M, et al. Health-related quality of life in long-term survivors of colorectal cancer and its association with all-cause mortality: a German cohort study. BMC cancer. 2018;18(1):1156.

23. Fried LP, Ferrucci L, Darer J, Williamson JD, Anderson G. Untangling the concepts of disability, frailty, and comorbidity: implications for improved targeting and care. The Journals of Gerontology Series A: Biological Sciences and Medical Sciences. 2004;59(3):M255-M63.

24. Magaji BA, Moy FM, Law CW, Sii HL, Roslani AC. Pattern of Health-Related Quality of Life and its Association among Patients with Colorectal Cancer. Asian Pacific Journal of Cancer Care. 2019;4(2):45-52.

25. Paika V, Almyroudi A, Tomenson B, Creed F, Kampletsas EO, Siafaka V, et al. Personality variables are associated with colorectal cancer patients' quality of life independent of psychological distress and disease severity. Psycho-Oncology: Journal of the Psychological, Social and Behavioral Dimensions of Cancer. 2010;19(3):273-82.

26. Wang J-W, Sun L, Ding N, Li J, Gong X-H, Chen X-F, et al. The association between comorbidities and the quality of life among colorectal cancer survivors in the People's Republic of China. Patient preference and adherence. 2016;10:1071.

27. Sapp AL, Trentham-Dietz A, Newcomb PA, Hampton JM, Moinpour CM, Remington PL. Social networks and quality of life among female long-term colorectal cancer survivors. Cancer: Interdisciplinary International Journal of the American Cancer Society. 2003;98(8):1749-58.

28. Trinquinato I, Marques da Silva R, Ticona Benavente SB, Cristine Antonietti C, Siqueira Costa Calache AL. Gender differences in the perception of quality of life of patients with colorectal cancer. Investigacion y educacion en enfermeria. 2017;35(3):320-9.

29. Stein D, Joulain F, Naoshy S, Iqbal U, Muszbek N, Payne K, et al. Assessing health-state utility values in patients with metastatic colorectal cancer: a utility study in the United Kingdom and the Netherlands. International journal of colorectal disease. 2014;29(10):1203-10.

30. Bours MJ, van der Linden BW, Winkels RM, van Duijnhoven FJ, Mols F, van Roekel EH, et al. Candidate predictors of health-related quality of life of colorectal cancer survivors: a systematic review. The oncologist. 2016;21(4):433.

31. Sharma A, Sharp D, Walker L, Monson J. Predictors of early postoperative quality of life after elective resection for colorectal cancer. Annals of Surgical Oncology. 2007;14(12):3435-42.

32. Jansen L, Koch L, Brenner H, Arndt V. Quality of life among long-term ( $\geqslant 5$ years) colorectal cancer survivorssystematic review. European Journal of Cancer. 2010;46(16):2879-88.

\section{Tables}

Table 1. Socio-demographic characteristics and EQ-5D-5L index values according to men $(n=49)$ and women $(n=56)$. 


\begin{tabular}{|c|c|c|c|c|c|c|c|}
\hline \multirow[t]{2}{*}{ Variable } & \multirow[t]{2}{*}{$N(\%)$} & \multicolumn{3}{|c|}{ EQ-5D-5L index } & \multicolumn{3}{|l|}{ сTTO } \\
\hline & & Men & Women & Total & Men & Women & Total \\
\hline & & $\begin{array}{l}\text { Mean } \\
\text { (SD) }\end{array}$ & Mean (SD) & $\begin{array}{l}\text { Mean } \\
(\mathrm{SD})\end{array}$ & $\begin{array}{l}\text { Mean } \\
\text { (SD) }\end{array}$ & $\begin{array}{l}\text { Mean } \\
\text { (SD) }\end{array}$ & $\begin{array}{l}\text { Mean } \\
(\mathrm{SD})\end{array}$ \\
\hline \multicolumn{8}{|l|}{ Age group, years } \\
\hline$<45$ & $\begin{array}{l}24 \\
(22.86)\end{array}$ & $0.67(0.09)$ & $0.42(0.09)$ & $0.49(0.04)$ & $0.54(0.04)$ & $0.65(0.25)$ & $0.54(0.04)$ \\
\hline $45-59$ & $\begin{array}{l}38 \\
(36.19)\end{array}$ & $0.57(0.07)$ & $0.48(0.06)$ & $0.46(0.06)$ & $0.50(0.06)$ & $0.54(0.06)$ & $0.52(0.04)$ \\
\hline $60-74$ & $\begin{array}{l}36 \\
(34.29)\end{array}$ & $0.50(0.07)$ & $0.28(0.08)$ & $0.45(0.05)$ & $0.44(0.08)$ & $0.51(0.08)$ & $0.49(0.05)$ \\
\hline$\geq 75$ & $7(6.67)$ & $0.51(0.05)$ & $-0.39(0.20)$ & $0.23(0.17)$ & $0.42(0.16)$ & $0.47(0.07)$ & $0.46(0.13)$ \\
\hline$F$ & & 4.08 & 4.08 & 4.34 & 3.99 & 4.88 & 4.19 \\
\hline$p$ value & & 0.04 & 0.03 & 0.03 & 0.04 & 0.03 & 0.04 \\
\hline \multicolumn{8}{|l|}{ Education status } \\
\hline Illiterate & $\begin{array}{l}12 \\
(11.43)\end{array}$ & $0.27(0.06)$ & $0.16(0.16)$ & $0.20(0.11)$ & $0.52(0.08)$ & $0.62(0.08)$ & $0.59(0.06)$ \\
\hline Primary & $\begin{array}{l}34 \\
(32.38)\end{array}$ & $0.65(0.05)$ & $0.36(0.07)$ & $0.47(0.05)$ & $0.53(0.08)$ & $0.55(0.05)$ & $0.54(0.04)$ \\
\hline Secondary & $\begin{array}{l}45 \\
(42.86)\end{array}$ & $\begin{array}{l}0.50 \\
(0.06)\end{array}$ & $0.45(0.07)$ & $0.49(0.04)$ & $0.50(0.05)$ & $0.48(0.08)$ & $0.49(0.04)$ \\
\hline University degree & $\begin{array}{l}14 \\
(13.33)\end{array}$ & $\begin{array}{l}0.52 \\
(0.08)\end{array}$ & $0.40(0.24)$ & $0.49(0.08)$ & $0.44(0.06)$ & $0.36(0.13)$ & $0.42(0.05)$ \\
\hline$F$ & & 4.11 & 4.98 & 5.14 & 2.89 & 2.18 & 3.01 \\
\hline$p$ value & & 0.04 & 0.02 & 0.001 & 0.15 & 0.34 & 0.11 \\
\hline \multicolumn{8}{|l|}{ Employment status } \\
\hline $\begin{array}{l}\text { Employed/self- } \\
\text { employed }\end{array}$ & $55(52.38)$ & $0.53(0.04)$ & $0.54(0.11)$ & $0.53(0.03)$ & $0.51(0.03)$ & $0.46(0.03)$ & $0.45(0.07)$ \\
\hline Unemployed/housewife & $50(47.62)$ & $0.52(0.05)$ & $0.35(0.05)$ & $0.37(0.04)$ & $0.26(0.10)$ & $0.53(0.04)$ & $0.52(0.02)$ \\
\hline$t$ & & 1.98 & 0.98 & 1.24 & 4.39 & 2.16 & 4.14 \\
\hline$p$ value & & 0.24 & 0.81 & 0.63 & 0.03 & 0.10 & 0.03 \\
\hline \multicolumn{8}{|l|}{$\begin{array}{l}\text { Monthly income (in } \\
\text { IRR) }\end{array}$} \\
\hline$<13,000,000$ & 41(39.05) & $0.47(0.05)$ & $0.36(0.08)$ & $0.42(0.05)$ & $0.40(0.04)$ & $0.46(0.15)$ & $0.47(0.06)$ \\
\hline $\begin{array}{l}13,000,000 \text { to } \\
29,999,999\end{array}$ & $41(39.05)$ & $0.59(0.06)$ & $0.33(0.07)$ & $0.44(0.05)$ & $0.48(0.06)$ & $0.48(0.05)$ & $0.50(0.03)$ \\
\hline$\geq 30,000,000$ & $23(21.90)$ & $0.53(0.08)$ & $0.52(0.12)$ & $0.53(0.06)$ & $0.62(0.06)$ & $0.61(0.05)$ & $0.54(0.04)$ \\
\hline$F$ & & 4.16 & 5.14 & 4.32 & 6.13 & 5.79 & 4.33 \\
\hline$p$ value & & 0.02 & 0.01 & 0.02 & 0.001 & 0.001 & 0.03 \\
\hline
\end{tabular}




\begin{tabular}{|llllllll|} 
Yes & $53(50.48)$ & $0.48(0.06)$ & $0.42(0.07)$ & $0.46(0.09)$ & $0.52(0.05)$ & $0.53(0.05)$ & $0.50(0.03)$ \\
\hline No & $52(49.52)$ & $0.45(0.05)$ & $0.30(0.06)$ & $0.44(0.04)$ & $0.46(0.03)$ & $0.52(0.05)$ & $0.52(0.04)$ \\
\hline$t$ & & 1.88 & 3.18 & 2.24 & 3.28 & 1.02 & 1.12 \\
\hline value & & 0.21 & 0.04 & 0.21 & 0.03 & 0.16 & 0.11 \\
& & & & & & & \\
\end{tabular}

cTTO = Composite Time Trade-Off; EQ-5D-5L =EuroQol-5 Dimensions-5 Levels

Table 2. Clinical characteristics and EQ-5D-5L index values according to gender $(\mathrm{N}=105)$ 


\begin{tabular}{|c|c|c|c|c|c|c|c|}
\hline \multirow[t]{2}{*}{ Variable } & \multirow[t]{2}{*}{$N(\%)$} & \multicolumn{3}{|c|}{ EQ-5D-5L index } & \multicolumn{3}{|l|}{ сTTO } \\
\hline & & Male & Female & Total & Male & Female & Total \\
\hline SEER stage classification & & $\begin{array}{l}\text { Mean } \\
\text { (SD) }\end{array}$ & $\begin{array}{l}\text { Mean } \\
\text { (SD) }\end{array}$ & $\begin{array}{l}\text { Mean } \\
\text { (SD) }\end{array}$ & $\begin{array}{l}\text { Mean } \\
\text { (SD) }\end{array}$ & $\begin{array}{l}\text { Mean } \\
\text { (SD) }\end{array}$ & $\begin{array}{l}\text { Mean } \\
\text { (SD) }\end{array}$ \\
\hline Localized & $\begin{array}{l}30 \\
(28.57)\end{array}$ & $0.53(0.06)$ & $0.45(0.04)$ & $0.47(0.06)$ & $0.59(0.04)$ & $0.52(.05)$ & $0.53(0.05)$ \\
\hline Regionalized & $\begin{array}{l}61 \\
(58.09)\end{array}$ & $0.48(0.11)$ & $0.41(0.11)$ & $0.40(0.08)$ & $0.51(0.03)$ & $\begin{array}{l}0.49 \\
(.12)\end{array}$ & $\begin{array}{l}0.50 \\
(0.08)\end{array}$ \\
\hline Distant & $\begin{array}{l}14 \\
(13.34)\end{array}$ & $0.36(0.07)$ & $0.31(0.03)$ & $0.33(0.05)$ & $0.41(0.02)$ & $\begin{array}{l}0.34 \\
(.08)\end{array}$ & $\begin{array}{l}0.43 \\
(0.06)\end{array}$ \\
\hline F & & 5.31 & 5.08 & 5.23 & 6.13 & 5.79 & 4.33 \\
\hline$P$ value & & 0.001 & 0.001 & 0.001 & 0.001 & 0.001 & 0.03 \\
\hline \multicolumn{8}{|l|}{$\begin{array}{l}\text { Duration of } \\
\text { disease(months) }\end{array}$} \\
\hline$<6$ & $\begin{array}{l}33 \\
(31.43)\end{array}$ & $0.61(0.05)$ & $0.29(0.09)$ & $0.44(.06)$ & $0.55(0.07)$ & $0.64(.05)$ & $\begin{array}{l}0.60 \\
(0.04)\end{array}$ \\
\hline 6-11 & $\begin{array}{l}30 \\
(28.57)\end{array}$ & $0.51(0.06)$ & $0.39(0.09)$ & $0.45(.05)$ & $0.47(0.06)$ & $0.48(.08)$ & $\begin{array}{l}0.47 \\
(0.05)\end{array}$ \\
\hline $12-23$ & $\begin{array}{l}17 \\
(16.19)\end{array}$ & $0.26(0.11)$ & $0.48(0.08)$ & $0.37(.07)$ & $0.38(0.04)$ & $0.48(.06)$ & $\begin{array}{l}0.46 \\
(0.04)\end{array}$ \\
\hline$\geq 24$ & $\begin{array}{l}25 \\
(23.81)\end{array}$ & $0.59(0.07)$ & $0.36(0.13)$ & $0.51(.06)$ & $0.52(0.07)$ & $0.44(.12)$ & $\begin{array}{l}0.49 \\
(0.06)\end{array}$ \\
\hline F & & 2.78 & 1.79 & 1.99 & 2.39 & 4.16 & 3.11 \\
\hline$P$ value & & 0.33 & 0.97 & 0.76 & 0.11 & 0.04 & 0.09 \\
\hline \multicolumn{8}{|l|}{ Comorbidity } \\
\hline 0 & $\begin{array}{l}66 \\
(62.86)\end{array}$ & $0.58(0.04)$ & $0.41(0.05)$ & $0.47(.03)$ & $0.55(0.07)$ & $\begin{array}{l}0.56 \\
(.10)\end{array}$ & $\begin{array}{l}0.56 \\
(0.06)\end{array}$ \\
\hline 1 & $\begin{array}{l}23 \\
(21.90)\end{array}$ & $0.55(0.11)$ & $0.35(0.11)$ & $0.43(.07)$ & $0.49(0.04)$ & $0.52(.05)$ & $0.51(0.03)$ \\
\hline$\geq 2$ & $\begin{array}{l}16 \\
(15.24)\end{array}$ & $0.53(0.09)$ & $0.25(0.14)$ & $0.40(.09)$ & $0.41(0.12)$ & $\begin{array}{l}0.50 \\
(.05)\end{array}$ & $\begin{array}{l}0.46 \\
(0.06)\end{array}$ \\
\hline F & & 3.99 & 4.98 & 4.13 & 4.02 & 4.54 & 4.51 \\
\hline$P$ value & & 0.04 & 0.01 & 0.03 & 0.04 & 0.02 & 0.02 \\
\hline
\end{tabular}

cTTO = Composite Time Trade-Off; EQ-5D-5L =EuroQol-5 Dimensions-5 Levels

Table 3. BetaMix model of the EQ-5D-5L index and cTTO values 


\begin{tabular}{|c|c|c|c|c|c|c|c|c|}
\hline Variable & $\mathbf{N}(\%)$ & EQ-5D-5 & index & & cTTO & & & \\
\hline $\begin{array}{l}\text { Independent } \\
\text { Variables }\end{array}$ & Coef & $d y / d x$ & SE & $\begin{array}{l}\text { [95\% Conf. } \\
\text { Interval] }\end{array}$ & Coef & $d y / d x$ & SE & $\begin{array}{l}\text { [95\% } \\
\text { Conf. } \\
\text { Interval] }\end{array}$ \\
\hline \multicolumn{9}{|l|}{ Gender } \\
\hline Female & $-0.0731^{\star}$ & -0.4312 & 0.0221 & $\begin{array}{c}{[-0.1164} \\
-0.0510]\end{array}$ & $-0.0823^{\star}$ & -0.4312 & 0.0312 & $\begin{array}{c}{[-0.1244} \\
-0.0632]\end{array}$ \\
\hline \multicolumn{9}{|l|}{ Age } \\
\hline $45-59$ & 0.0412 & 0.0581 & 0.0561 & $\begin{array}{r}{[-0.0687} \\
0.0973]\end{array}$ & $0.0794^{*}$ & 0.0671 & 0.0198 & $\begin{array}{c}{[-0.0767} \\
0.0992]\end{array}$ \\
\hline $60-74$ & -0.0711 & -0.0782 & 0.0271 & $\begin{array}{l}{[-0.1242} \\
-0.0440]\end{array}$ & $-0.0823^{*}$ & -0.0798 & 0.0206 & $\begin{array}{c}{[-0.2511} \\
-0.0564]\end{array}$ \\
\hline$\geq 75$ & $-0.0981^{*}$ & -0.0831 & 0.0231 & $\begin{array}{c}{[-0.1433} \\
-0.0750]\end{array}$ & $-0.0956^{\star}$ & -0.0901 & 0.0214 & $\begin{array}{c}{[-0.1895} \\
-0.0875]\end{array}$ \\
\hline \multicolumn{9}{|c|}{ Monthly income (IRR) } \\
\hline $\begin{array}{l}13,000,000 \text { to } \\
29,999,999\end{array}$ & $0.0986^{*}$ & 0.0938 & 0.0112 & $\begin{array}{c}{[0.0766} \\
0.1098]\end{array}$ & $0.2137 \star$ & 0.8865 & 0.0432 & $\begin{array}{c}{[0.1166} \\
0.1268]\end{array}$ \\
\hline$\geq 30,000,000$ & $0.1075^{\star}$ & 0.9191 & 0.0108 & $\begin{array}{l}{[0.0863} \\
0.1183]\end{array}$ & $0.1189 *$ & 1.0125 & 0.0215 & $\begin{array}{c}{[0.0986} \\
0.1511]\end{array}$ \\
\hline \multicolumn{9}{|c|}{ Comorbidity number } \\
\hline 1 & $-0.0765^{\star}$ & -0.0812 & 0.0184 & $\begin{array}{c}{[-0.1125} \\
-0.0581]\end{array}$ & -0.0474 & -0.0532 & 0.0293 & $\begin{array}{c}{[-0.1215} \\
-0.0621]\end{array}$ \\
\hline$\geq 2$ & $-0.0831^{\star}$ & -0.0723 & 0.0125 & $\begin{array}{c}{[-0.1076} \\
-0.0706]\end{array}$ & -0.0321 & -0.0954 & 0.0354 & $\begin{array}{c}{[-0.1198} \\
-0.0616]\end{array}$ \\
\hline \multicolumn{9}{|l|}{$\begin{array}{l}\text { SEER stage } \\
\text { classification }\end{array}$} \\
\hline Regionalized & $-0.0892^{*}$ & -0.0923 & 0.0213 & $\begin{array}{c}{[-0.1309} \\
-0.0679]\end{array}$ & $-0.0989 *$ & -0.0897 & 0.0207 & $\begin{array}{l}{[-0.1209} \\
-0.0749]\end{array}$ \\
\hline Distant & $-0.1020 *$ & -0.1453 & 0.0226 & $\begin{array}{c}{[-0.1463} \\
-0.0794]\end{array}$ & $-0.1120^{\star}$ & -0.0983 & 0.0239 & $\begin{array}{l}{[-0.1382} \\
-0.0684]\end{array}$ \\
\hline$F$ & $1.3421^{\star}$ & 1.6787 & 0.0987 & $\begin{array}{c}{[1.1486} \\
1.4408]\end{array}$ & $1.1241^{\star}$ & 1.0783 & 0.0745 & $\begin{array}{l}{[1.3216} \\
1.8518]\end{array}$ \\
\hline
\end{tabular}

cTTO = Composite Time Trade-Off; EQ-5D-5L =EuroQol-5 Dimensions-5 Levels

*significant at level $5 \%$

\section{Figures}




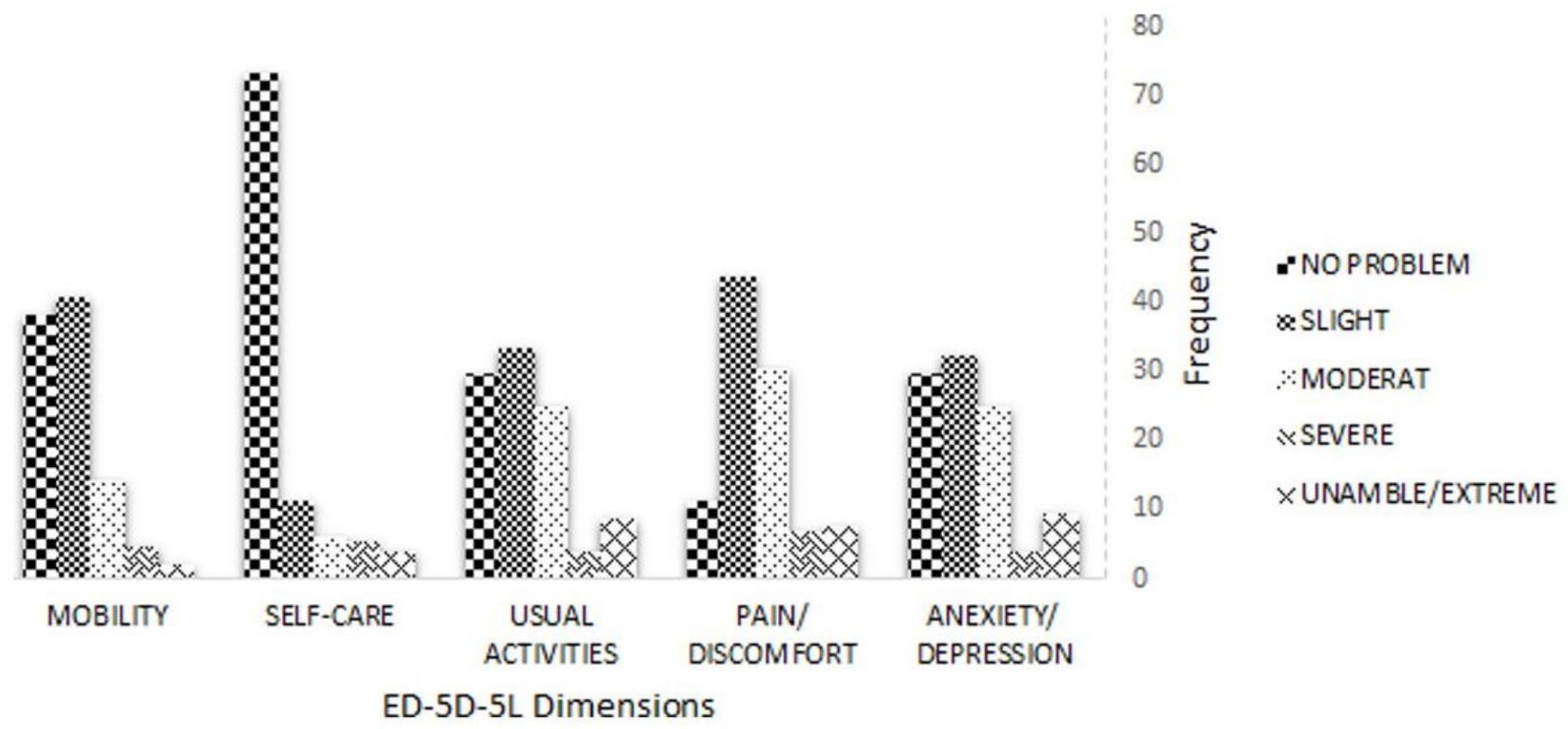

Figure 1

Percentage of problem on each of the EQ-5D-5L dimensions 